http://doi.org/10.35784/iapgos.914

\title{
THE INCREASE OF THE ENERGY EFFICIENCY OF THE RADIO EQUIPMENT BASED ON THE USE OF MODULATION BY ORTHOGONAL HARMONIC CARRIERS
}

\author{
Sergey Toliupa ${ }^{1}$, Vladimir Nakonechnyi ${ }^{1}$, Alexander Trush ${ }^{2}$ \\ ${ }^{1}$ Taras Shevchenko National University of Kyiv, Department of Cybersecurity and Information Protection, Kyiv, Ukraine \\ ${ }^{2}$ Taras Shevchenko National University of Kyiv, Department of Network and Internet Technologies, Kyiv, Ukraine
}

Abstract. Most of the theoretical results, as well as methods using OFDM modulation, are obtained in order to increase the rate of information transmission with energy constraints and the bandwidth. For broadband radio access systems, this task is primarily due to the commercial purpose of these systems and the desire of the communications developers to provide high-speed wireless access to the Internet as much as possible at the same time. This article is devoted to the issue of increasing the energy efficiency of radio equipment using modulation orthogonal harmonic carriers under conditions of intentional interference and frequency-selective fading while ensuring a given level of reliability and speed of information transmission.

Keywords: radio communication, carrier, signal, noise, energy efficiency

\section{ZWIEKSZENIE WYDAJNOŚCI ENERGETYCZNEJ SPRZETU RADIOWEGO W OPARCIU O STOSOWANIE MODULACJI PRZEZ ORTOGONALNE HARMONICZNE}

Streszczenie. Większość wyników teoretycznych, a także metod wykorzystujacych modulację OFDM, uzyskuje się w celu zwiększenia szybkości transmisji informacji z ograniczeniami energetycznymi i przepustowością. W przypadku szerokopasmowych systemów dostępu radiowego zadanie to wynika przede wszystkim z komercyjnego celu tych systemów i chęci twórców komunikacji, aby zapewnić szybki bezprzewodowy dostęp do Internetu w jak największym stopniu $w$ tym samym czasie. Artykut poświęcony jest zwiększeniu wydajności energetycznej urządzeń radiowych $z$ wykorzystaniem modulacji ortogonalnych nośników harmonicznych $w$ warunkach zamierzonego zakłócania i selektywnego opadania częstotliwości, przy jednoczesnym zapewnieniu określonego poziomu niezawodności i prędkości transmisji informacji.

Słowa kluczowe: komunikacja radiowa, nośna, sygnał, hałas, efektywność energetyczna

\section{Introduction}

Methods of optimizing OFDM signals, improvement of algorithms for their formation and processing have been the subject of intensive theoretical research in recent years. However, most of the theoretical results, as well as methods implemented in existing radio communication systems (SRZs) using OFDM modulation, are obtained to increase the speed of information transmission with energy constraints and bandwidth (increasing the frequency efficiency of the system). For broadband radio access systems, this task is primarily due to the commercial purpose of these systems and the desire of the communications developers to provide high-speed wireless access to the Internet as much as possible at the same time. For radio communication systems, where, as a rule, the information load on communication lines is known, the task of increasing energy efficiency with restrictions on bandwidth, bandwidth and reliability [1-3] is more relevant.

Consequently, the task of increasing the energy efficiency of SRH in the conditions of multipath of radio waves is relevant and has not only a theoretical but also a great application value for ensuring the necessary level of readiness of radio communication systems by increasing the timeliness, probability and concealment of management.

\section{Theoretical indicators for improving energy efficiency of radio communication systems (SRZ)}

An important indicator of the effectiveness of radio communication systems (SRZ) is energy efficiency, which, the greater it is, the less energy is needed to transmit one bit of information. Advantages of increasing energy efficiency are obvious: a minimization of transmitter radiation power, an improvement of electromagnetic compatibility of radio-electronic means, an increase of concealed transmission of information, a minimization of power consumption [4].

The essence of the proposed method is to adapt the values of the parameters of the OFDM signal of the radio communication means of destination, which are optimal for the criterion of the maximum of the energy efficiency indicator with a given reliability of information transmission and throughput.

Setting objectives.

Specified: parameters of the transmitter and the communication channel $\Psi=\left\{\psi_{i}\right\}, i=\overline{1,10}$, where $\psi_{1} \ldots \psi_{10}-$ the number of subcarriers, the power of the useful signal, the ratio of the signal/noise in the channel, the operating frequency, the type of modulation, the rate of information transmission (required bandwidth), set of correcting codes with appropriate parameters: length of the code combination, the speed of the correction code, the value of the code distance, the limit value of the signal-tonoise ratio in the channel, at which the correction code begins to win with modulation without coding. The initial mode of operation, which provides the required speed of information $v_{i \text { parm }}$ transmission, involves the use of all subcarriers and the least speed correction code.

It is necessary: to determine the optimal values of the signal parameters (the number of active subcarriers and their numbers, the correction code, the transmitter power and its distribution among the subchannels), at which the energy efficiency of the SRZ $\beta_{E}$ is maximized when the limitations on the probability of a false signal $P_{b} \leq P_{\mathrm{b} \text { parm }}$ reception and the rate of transmission in the channel $v_{i} \geq v_{\text {i parm }}$.

Restrictions: the type of correction code - ergonomic codes with speed $R=0.5-0.9$; type of signal - FM-4; number of subcarriers $\mathrm{N}=256$; the maximum acceptable probability of the false reception of signals $P_{\mathrm{b} \text { parm }}=10^{-5}$.

Assumption: the state of the transmission characteristic of the $\mathrm{H}$ connection channel is known and does not change during the transmission of the symbol before transmitting the next OFDM symbol:

$$
H_{\text {zag }}=H_{1}, H_{2}, \ldots, H_{N}=\sum_{i=1}^{N} H_{i} \text {, where } H_{i} \text { is the transfer }
$$

characteristic of the $i$-subchannel; the amplitude characteristic of the power amplifier of the transmitter is linear - there are no nonlinear distortions of the signal. 
The task of determining the values of the parameters of the OFDM signal with the maximum energy efficiency indicators is reduced to a typical optimization problem [6]. The system of equations for solving the optimization problem has the form

$$
\left\{\begin{array}{l}
\beta_{E}=F_{1}\left(v_{\mathrm{i}}, \Delta F, M, n, R, d, P_{\mathrm{s}}, N_{\mathrm{A}}\right) \rightarrow \max \\
P_{\mathrm{b}}=F_{2}\left(P_{\mathrm{s}}, M, n, R, d, N_{\mathrm{A}}\right) \leq P_{\mathrm{b} \text { parm }} \\
v_{\mathrm{i}}=F_{3}\left(M, R, N_{\mathrm{A}}\right) \geq v_{\mathrm{i} \text { parm }}
\end{array}\right.
$$

where $n$ is the length of the code combination, $P_{s}$ is the signal strength, $M$ is the signal strength dimension, $R$ is the correction code rate $R=k / n, k$ is the number of information bits in the code combination length $n, \mathrm{~d}$ is the code distance, $N_{A}$ is the number of active subcarriers, $\Delta F$ - the width of the spectrum of the signal.

Let's expand the function of the system of equations (1). Information speed is defined as

$$
v_{i}=\frac{B}{T_{S}}=\frac{N \cdot \log _{2} M \cdot R}{T_{S}}
$$

where $T_{s}$-duration of the symbol; $B$ is the number of information bits transmitted in one OFDM character. In the case of adaptive power distribution (ARP), the signal/noise ratio at the input of the receiver is aligned in all sub-channels and will take values $Q_{\text {mid }}^{2}$. Let's express the value of the average of all sub-channels of the signal/noise ratio:

$$
Q_{\text {mid }}^{2}=P_{s} \cdot \frac{k}{n} / \sum_{i=1}^{N_{A}} G_{0 i}
$$

where $G_{0 i}$ is the spectral density of the noise power in the $i$-th subchannel.

Energy efficiency is determined by [2] as

$$
\beta_{E}=v_{i} / Q_{\text {mid }}^{2}
$$

The probability of an error in the formula when applying the correction code is determined by the expression

$$
P_{\text {pom }} \geq \sum_{j=s_{\text {vip }}+1}^{n} C_{n}^{j} P_{\text {pom }}^{j}\left(1-P_{\text {pom }}\right)^{n-j}
$$

where $P$ - the probability of erroneous decoding of the code combination $s_{\text {vip }}=(d-1) / 2$ - the multiplicity of errors that the code corrects, $j$ - the multiplicity of the error in the block of $n$ elements, $P_{\mathrm{pom}}^{j}-$ the probability of error occurrence in the sequence of transmitted code elements, $C_{n}^{j}=n ! / j !(n-j) !-$ the binomial coefficient, which is equal to the number of different combinations of $\mathrm{j}$ errors in the block with $\mathrm{n}$ characters. The value is determined by the type of signal modulation and is calculated taking into account the encoding rate $R$ :

$$
P_{\text {pom }}=\left[1-\Phi\left[\sqrt{2 Q_{\text {mid }}^{2} R}\right]\right]
$$

where $\Phi$ is the Krampa function [2].

Then, taking into account the formulas (3) and (4)

$$
P_{\mathrm{b}}=\sum_{j=(d+1) / 2}^{n} C_{n}^{j} \cdot\left[1-\Phi \sqrt{2 Q_{\mathrm{mid}}^{2}}\right]^{j} \cdot\left[1-\left(1-\Phi \sqrt{2 Q_{\mathrm{mid}}^{2}}\right)\right]^{n-j}
$$

From the analysis of system (1), it follows that its computational complexity in real time is not acceptable. However, if you somehow change the order of the task, the desired result can be obtained more easily. First, with fixed power $P_{s}$, the values of the parameters that provide the minimum probability of error $P_{b}$ are found. Since the values of $\Delta F, M, T_{S}$, according to the output data are constant, they can be replaced by $B$. Thus, the system of equations for solving the optimization problem is transformed into the form:

$$
\left\{\begin{array}{l}
P_{\text {pom }}=\sum_{j=(d+1) / 2}^{n} C_{n}^{j} \cdot\left[1-\Phi \sqrt{2 Q_{\text {mid }}^{2}}\right]^{j} . \\
\cdot\left[1-\left(1-\Phi \sqrt{2 Q_{\text {mid }}^{2}}\right)\right]^{n-j} \rightarrow \min \\
B=N_{\mathrm{A}} \cdot R \geq B_{\text {parm }} \\
Q_{\text {mid }}^{2} \geq Q_{\text {bor }}^{2} \\
P_{\mathrm{s}}=\text { const }
\end{array}\right.
$$

It is advisable to solve the presented problem of conditional discrete optimization using a directed selection of valid variants using an iterative algorithm.

The technique of choosing the optimal values of the OFDM signal parameters, the block diagram of the implementation, algorithm of which is presented in Fig. 1, consists of the following steps.

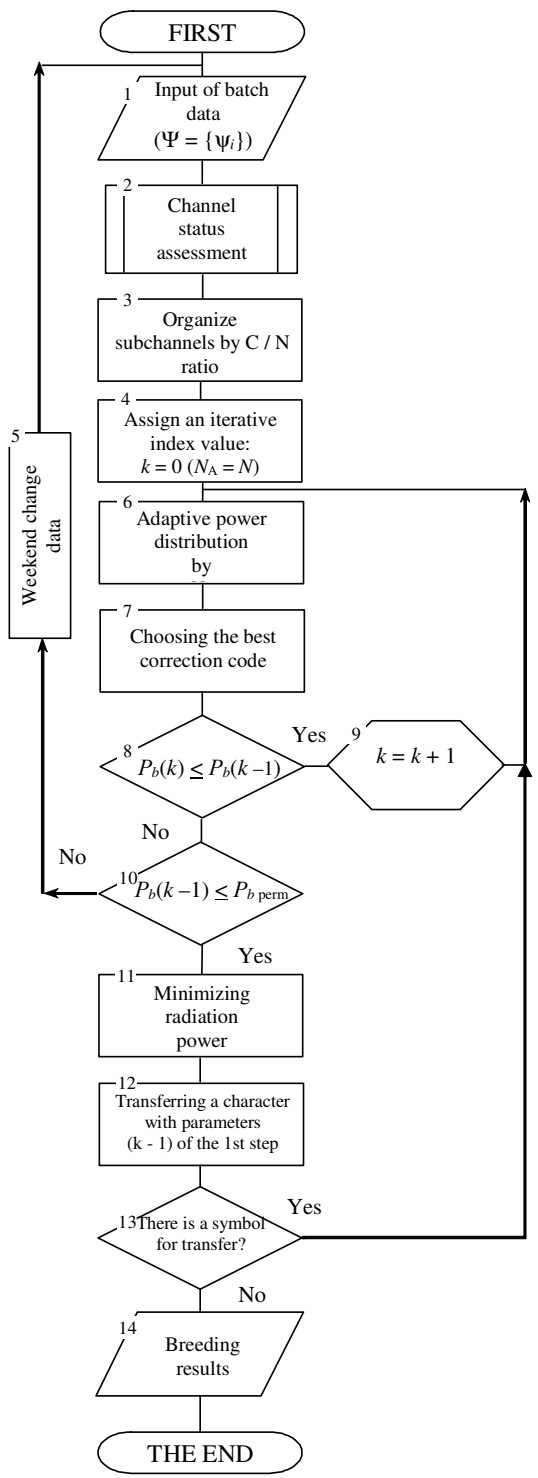

Fig. 1. The block diagram of the algorithm for implementing the selection method of optimal values of the OFDM signal, depending on the status of the link

Input of input data. The parameters of the transmitter and communication channel $\Psi=\left\{\psi_{i}\right\}$, are entered, as well as the admissible value of the probability of false signal $P_{\mathrm{b} \text { parm }}$ reception and the minimum required information transmission rate $v_{\mathrm{i} \text { parm }}$. 
Assessment of the transmission characteristics of the communication channel. At this stage, the state of the multichannel communication channel is evaluated and its transfer characteristic is determined.

Arranging subchannels in order of decreasing ratio of signal/noise at the receiver input. At this stage, the results of evaluation of the transfer characteristics of the channel are an assignment of sequence numbers to each subchannel in the order of decreasing ratio of signal/noise (worse subchannels have larger sequence numbers): $Q_{1}^{2} \geq Q_{2}^{2} \geq \ldots \geq Q_{N}^{2}$

Assigning the value of the iteration index. The choice of the optimal values of the OFDM signal parameters is an iterative procedure for identifying the step numbers from which the iteration index $k$ is entered. The maximum possible number of active subcarriers $\left(N_{A}=N\right)$ corresponds to $k=0$. At each subsequent step of the iterative procedure $(k=k+1)$, the worstcase subcarrier signal/noise ratio $\left(N_{A}=N-1\right)$ is disconnected. Disconnecting subcarriers with low signal/noise ratio reduces the harmful effects of interference and frequency-selective fading on the probability of false reception.

Adaptive power distribution between active subcarriers. At this stage, in the first place, the average value for all active $Q_{\text {mid }}^{2}$ subcarriers is determined:

$$
Q_{\text {mid }}^{2}(k)=\frac{1}{N_{A}} \sum_{i=1}^{N_{A}} Q_{i}^{2}
$$
follows:

Then, the coefficient of power distribution is determined as

$$
K_{i}(k)=\frac{Q_{\mathrm{mid}}^{2}(k)}{Q_{i}^{2}}
$$

Choosing the best correction code. At this stage, from the finite number of correction codes determined by the initial data, those that meet the information rate requirements are selected first and for them the average signal/noise ratio in the channel exceeds the limit value $Q_{\mathrm{bor}}^{2}$ at which the code begins to gain. Then, by sequential scanning, the code is determined which provides the best noise immunity of the acceptance:

$$
\left\{\begin{array}{l}
v_{i}(k) \geq v_{i \text { parm }}, Q_{\mathrm{bor}}^{2}<Q_{\mathrm{mid}}^{2}(k) \\
P_{b}(k)=\min
\end{array}\right.
$$

If no code satisfies the condition, then at this stage the mode is selected without the use of interference-free encoding.

Checking the conditions for the iteration procedure. At this stage, the condition is checked

$$
P_{b}(k) \leq P_{b}(k-1)
$$

Under condition, the value of the iteration index $(k=k+1)$ is increased, the next subcarrier with the lowest signal/noise ratio is disconnected, and the repeat of paragraphs 4-7 is performed. If the condition is not met, the iterative procedure stops and the condition is checked

$$
P_{b}(k-1) \leq P_{b \text { parm }}
$$

Minimization of radiation power. At this stage, if the condition is fulfilled, the total radiation power of the transmitter is reduced to a certain threshold, at which the probability of error becomes equal to the maximum allowable:

$$
P_{b} \leq P_{\mathrm{b} \text { parm }}
$$

Consequently, the optimal values of the parameters of the next OFDM symbol are determined: $N_{\mathrm{A}}, K_{i}, n, k, d, P_{\mathrm{s}}$, the information about the values that is transmitted as a part of the service information for the counter station.

\section{An algorithm for implementing a method of selecting optimal OFDM signal values}

It is obvious that the proposed iteration procedure consists, in the gradual disconnection, of subcarriers with small gain factors (high power of effective noise), adaptive power distribution between active subcarriers for equalizing the transmission characteristics of the channel and the choice of correction code, which ensures the least probability of erroneous reception. After this, the reserve for noise immunity is exchanged to reduce the total radiation power of the transmitter (that is, the power decreases until the probability of error becomes equal to the allowable value

$$
P_{b} \leq P_{\mathrm{b} \text { parm }}
$$

The sub-carrier disconnection procedure continues until the disconnection of another subcarrier results in an increase of the probability of false acceptance in the system.

After that, one needs to find the value at which, in an explicit form, it is impossible to solve equation (5) with respect to the variable. Therefore, for solution (5), it is expedient to apply the half-division method.

The proposed iteration procedure is the gradual disconnection of subcarriers with small gain factors (high power of effective noise), adaptive power distribution between active subcarriers in order to equalize the transmission characteristics of the channel and the choice of the correction code, which ensures the least probability of erroneous reception [7-8]. After this, the reserve for noise immunity is exchanged to reduce the total radiation power of the transmitter (that is, the power decreases until the probability of error becomes equal to the allowable value

$$
P_{b} \leq P_{\mathrm{b} \text { parm }} \text {. }
$$

To evaluate the effectiveness of the proposed methodology, using the recommendations, an imitation model was developed in the MathCad programming environment.

The program that implements the developed model simulates the work of the radio line for the following cases:

1) without adaptation in radio traffic (system 1);

2) with the adaptation of the radiation power, that is, the ARP algorithm (system 2).

3) using the developed method of selecting the optimal values of the OFDM signal parameters, depending on the state of the communication channel (system 3 ).

Systems 1 and 2 operate using the least speed code from a given set $(R=0.5)$ and do not use the sub-carrier disconnection algorithm. It can be assumed that system 1 reproduces the algorithm of the IEEE 802.11a standard using OFDM modulation. However, it should be noted that the evaluation of efficiency compared with this system is rather conditional, since in the case of deterioration of the connection quality to the inadmissible level the IEEE 802.11a system passes to another operating frequency [9].

The assessment of the effectiveness of the developed methodology was carried out by comparing the energy efficiency indicators for systems 1, 2 and 3 with given identical output data. Fig. 2 shows the dependence of the power gain of the transmitter $\Delta P_{c}$ for the three systems from the average signal/noise ratio in the channel at a given depth of frequency-selective fade.

The abscissa line corresponds to the use of the maximum possible transmitter power, that is, in principle, it is impossible to implement positive values in the axis (under such conditions the system cannot provide the exchange of information with a given quality), and calculations for this area were conducted to compare the efficiency of systems 1 to 3 to each other. From the charts it is clear that the system 3 allows to increase the energy efficiency index, depending on the depth of selective fading, by a value of $5-7.5 \mathrm{~dB}$ in comparison to system 1 and by $2-3 \mathrm{~dB}$ in comparison to system 2 . 


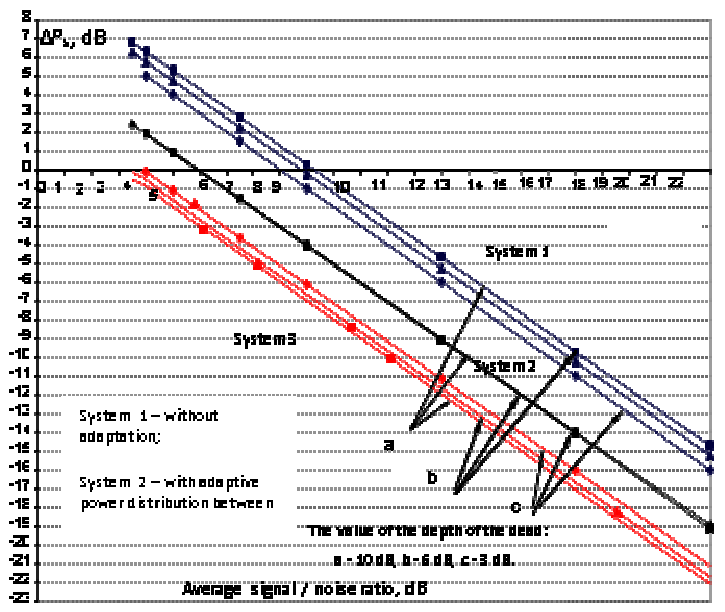

Fig. 2. Dependence of the growth of the transmitter power from the average signal/noise ratio in the channel for different values of the fading depth

Fig. 3 shows the dependence of the transmitter power gain on the target bandwidth for a channel with an average signal-to-noise ratio of $10 \mathrm{~dB}$ and a dead-end depth of $6 \mathrm{~dB}$.

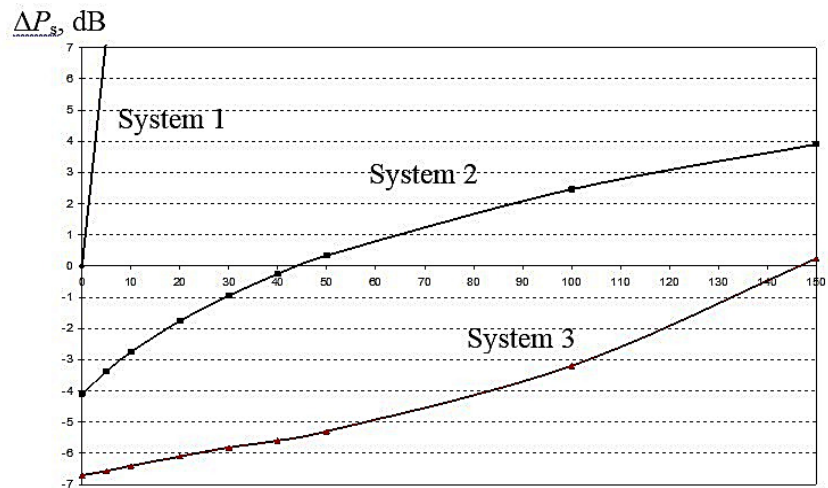

Fig. 3. Dependence of the power gain of the transmitter on the width of intentional bandwidth for a medium-sized channel, $10 \mathrm{~dB}$ signal and noise, and $6 \mathrm{~dB}$ fading depth

The noise power is selected to produce a $0 \mathrm{~dB}$ signal/noise ratio in the subchannel of the system 1 . It can be seen that system 3 in such conditions is capable of transmitting information at a bandwidth of a powerful interference that overlaps about $50 \%$ of the signal spectrum. For system 2 , it is sufficient to diminish the noise of the signal to less than $20 \%$ of the signal spectrum, to disable it, and system 1 stops functioning with the given quality when overcoming the interruption of at least one subcarrier.

The estimation of the computational complexity of the implementation of the developed method showed that for the given output data and when using the ADSP-21261 processor, the formation of a signal with optimal parameter values can be carried out in real time with a delay required for the transmission of information about these values through the service feedback channel.

\section{Conclusion}

The optimal values of the signal parameters for a particular state of the communication channel are determined from the finite number of valid variants, which simplifies the practical implementation of the modem equipment of adaptive radio communication systems. The difference of the proposed methodology is that the optimal values of the OFDM parameters are determined by the criterion of the maximum of the energy efficiency in the conditions of frequency-selective fade and the effect of intentional noise, and the signal parameters the values of which are determined when solving the optimization problem are: the number of active subcarriers, the type of correction code, the transmitter power and the amplification frequencies of the frequency subchannels.

A positive effect of the implementation of the developed methodology is provided by the following interconnected factors: the maximization of energy efficiency; the minimization of transmitter power; the improvement of electromagnetic compatibility of radio-electronic means; the increase of the secret of the information transfer; the minimization of energy consumption.

\section{References}

[1] Coleri S., Ergen M., Puri A., Bahai A. : Channel estimation techniques based on pilot arrangement in OFDM systems. IEEE Trans. Broadcast 48(3)/2002, 223-229.

[2] Morelli M.: A Comparison of Pilot-Aided Channel Estimation Methods for OFDM Systems. IEEE Trans. on Signal Processing 49(12)/2001, 3065-3073.

[3] Kuvshinov O. V.: OFDM technology: an overview of problems and ways of solving them. Communication 1/2008, 42-46.40.

[4] Pickholtz R. L.: Theory of Spread-Spectrum Communications. IEEE Trans. Commun. Com-30(5)/1982, 855-884.

[5] Edfors O., SandellM., van de Beek J. J. et al.: OFDM channel estimation by singular value decomposition. IEEE Trans. Commun. 46(7)/1998, 931-939.

[6] Li Y.: Robust channel estimation for OFDM systems with rapid dispersive fading channels. IEEE Trans. Commun. 46/1998, 902-915.

[7] Toliupa S., Gursky T. G., Voskolovich A. I.: An analysis of the method of evaluating the parameters of the channel's channels in the link. News of the Sovereign to the University of Information Technology 9(3)/2011, 194-204.

[8] Toliupa S., Babenko T., Parhomenko I.: The method of forming and signal processing aimed at improving stealth and energy efficiency. $2^{\text {nd }}$ International Conference Advanced Information and Communication Technologies (AICT), 2017, 304-308.

[9] Gursky T.G.: Mathematical model of radio line using OFDM technology in the conditions of influence of intentional interference. Proceedings of VITI NTU "KPI" 2/2008, 9-16.

\section{Prof. Sergey Toliupa}

e-mail: tolupa@i.ua

His scientific and practical interests are related to areas such as intelligent control systems, the direction of improving the efficiency of information technology, information security systems, cybersecurity and cyber defense. $\mathrm{He}$ is the author of 5 monographs and ove 150 scientific and methodological works, 16 textbooks and manuals.

http://orcid.org/0000-0002-1919-9174

\section{Prof. Vladimir Nakonechnyi}

e-mail: nvc2006@i.ua

His scientific and practical interests are related to areas such as intelligent control systems, the direction of improving the efficiency of information technology, information security systems, cybersecurity and cyber defense. $\mathrm{He}$ is the author of 4 monographs and over 80 scientific and methodological works, 7 textbooks and manuals.

http://orcid.org/0000-0002-0247-5400

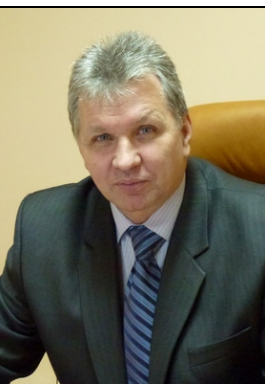

\section{Ph.D. Alexander Trush}

e-mail: trush.viti@gmail.com

His scientific and practical interests are related to areas such as information and communication systems and networks, systems of technical protection of information, cyber defense. He is the author of over 35 scientific and methodological works, 2 textbooks.

http://orcid.org/0000-0001-8473-9387
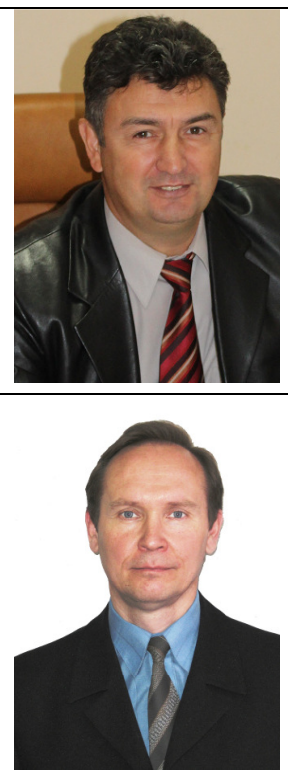

otrzymano/received: $15.11 .2019 \quad$ przyjęto do druku/accepted: 15.02 .2020 